\title{
Atrioventricular Canal Defects: Morphologic Features and Surgical Techniques
}

\author{
Koray Ak* \\ Department of Cardiovascular Surgery, Marmara University School of Medicive, Turkey
}

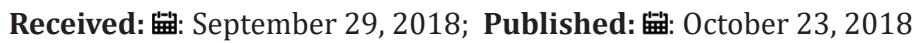

*Corresponding author: Koray Ak, Kalp ve Damar Cerrahisi AD, Sağlık Bakanlığı Marmara Universitesi, Pendik Egitim ve Arastirma Hastanesi, 4. Kat, Ustkaynarca Pendik, Istanbul, Turkey

Abbreviations: International Pediatric And Congenital Cardiac Coding (IPCCC); Atrial Septal Defect (ASD); Cardiopulmonary Bypass (CPB)

\section{Introduction}

After the first successful repair of an AV canal defect by $\mathrm{C}$. Walton Lillehei in 1955, there have been tremendous improvements in both surgical techniques and perioperative care of patients. Nowadays early mortality after surgical repair has dropped to less 3 to $4 \%$ in many parts of the world. On the other hand, in terms of complexity, the repair of an $\mathrm{AV}$ canal defect could be quite challenging for surgeons in some cases. When we look at Aristotle scoring system which grades congenital cardiac procedures with regard to their complexity (simple: 1.5 to very complex: 15), surgical repair of an complete AV canal has been still classified as a comlex procedure (Aristotle score 9) [1]. Therefore, in this paper we try to summarize current surgical techniques used for repair of this complex pathology.

\section{Surgical Anatomy and Classification of AV Canal Defects}

According to the International Pediatric and Congenital Cardiac Coding (IPCCC) system [2]; AV canal defects have classified into 4 main categories:
a) complete,
b) partial
c) intermediate/transitional and
d) AV canal with ventricular imbalance.

Common morphological features of AV canals are described as deficiency of a portion of the inlet interventricular septum, attachment of a portion of the AV valve to the septum and equal distances of two AV valves to the cardiac apex (Figure 1a). Due to the abnormal attachment of the anterior medial leaflet, the left ventricular outflow tract seems elongated and sometimes obstructed (Figure1b). That might be more prominent in patients with partial AV canals. In AV canal defects, aortic valve loses its wedged position between the left and the right $\mathrm{AV}$ valves.

From surgical point of view, one of the most important morphological features of $\mathrm{AV}$ canal defects is the location of the conduction system. Here, atrioventricular node is displaced inferiorly and posteriorly toward the coronary sinus due to the presence of an ostium primum ASD (Figure 1). With this regard, a special attention should be paid during surgical repair in order to prevent the development of complete AV block.

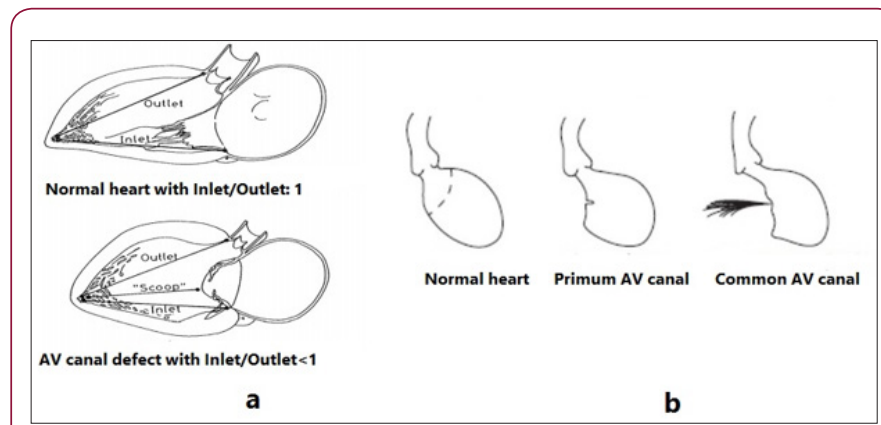

Figure 1:

a. Inlet/Outlet ratio in a normal heart is equal to 1 , and Inlet/Outlet ratio in a heart with AV canal defect is less than 1

b. left ventricular outflow tract in a normal heart and hearts with $\mathrm{V}$ canal defects.

Partial-Type: It is a crescent shaped defect of the atrial septum and is also named as an ostium primum atrial septal defect (ASD). Anatomically, bridging leaflets attach to the ventricular septum with leaving only an interatrial connection. Despite the presence of a single valve annulus, there are two valvular orifices. In partial AV 
canal, the AV valve has usually 6 components and the commissure between the left superior and inferior leaflet is called as cleft (Figure 2). Partial AV canals have varying degrees of malformation of the left $\mathrm{AV}$ valve, causing varying degrees of valvular regurgitation.

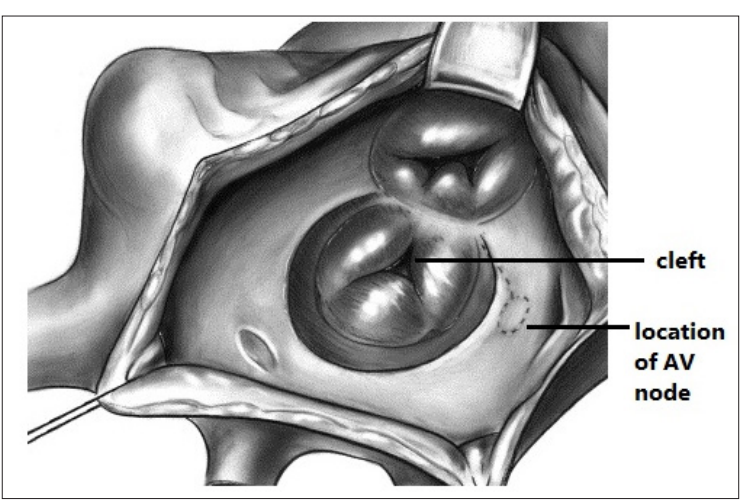

Figure 2: Partial AV canal defect with a cleft on the left atrioventricular valve.

Intermediate or Transitional Type: There is a primum ASD in association with a restrictive VSD with this type of the defect. This type is distinguished from complete AV canal two separate valvular orifices and the presence of a restrictive ventricular defect. Again, there is a single annulus, a common morphologic feature of all types of the defects.

AV Canal with Ventricular Imbalance: Due to the presence of asymmetrical commitment of the common $\mathrm{AV}$ valve to both ventricles, one of the ventricles remains hypoplastic (Figure 3). Single ventricle palliation or two ventricle repair could be options in surgical treatment of these patients.

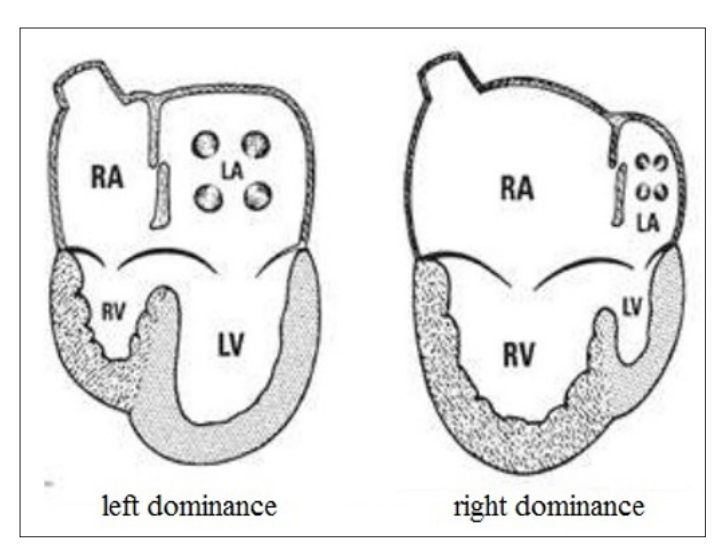

Figure 3: AV canal defects with ventricular imbalance.

Complete AV Canal: With this type of morphology, there are a large ostium primum atrial septal defect (ASD) and a large interventricular communication between the crest of the interventricular septum and the inferior aspect of the common valve. The valve might have 5 to 6 leaflets. There are always superior and inferior bridging leaflets. Based on the degree of bridging and chordal attachment of the superior bridging leaflet, complete AV canal is classified into 3 types by Rastelli in 1966 (Figure 4).

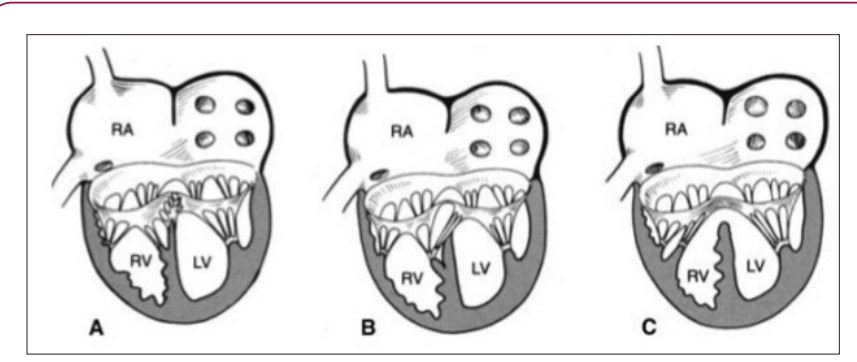

Figure 4: Rastelli classification of complete AV canal defects.

a) Type A: The superior bridging leaflet has chordal attachments to the septum and normal arrangement of the right ventricular medial papillary muscle.

b) Type B: The superior bridging leaflet extends farther into the right ventricle, being attached to an anomalous right ventricular papillary muscle arising from the trabecula septomarginalis.

c) Type C: The free-floating superior bridging leaflet extends even farther into the right ventricle and is attached to an anterior papillary muscle.

\section{Surgical Techniques}

For surgical repair of all types of AV canal defects, aortic and bicaval cannulation (metal-tipped angled cannulas) is done in a standard fashion. Surgical repair of AV canal defects are usually done under either normothermic or mild to moderately hypothermic cardiopulmonary bypass (CPB) and cold blood cardioplegia in our institution. Repair is standardly perfomed through the right atriotomy.

\section{Repair of Partial AV Canal Defects}

Repair of partial AV canal defects starts by floating of the valve with injection of saline (or cold cardioplagia solution in some centers). Injection of testing solution should be given to prevent frothing in the left heart chambers. Frothing might cause formation of microbubles within the left heart and, consequently, results in coronary embolisation and ventricular dysfunction during weaning off CPB. During testing of the valve, particular attention should be given to ensure accurate approximation of the cleft. Firstly, we start putting an approximation suture (usually 6 or $7 / 0$ Prolene) from the free edge that is defined by the origin of the cords. Then multiple simple sutures are employed till the nadir of the cleft. Then, repeat testing of the valve comfirms the competency of the valve. In case with dilated AV annulus, centrally located insufficiency persists after closure of the cleft and it can be treated by placing commisuroplasty sutures. After repair of cleft, an appropriately sized patch is sutured to the leaflet tissue between the left and right $\mathrm{AV}$ valves, that necessitates special attention. Here, suturing the patch material to the leaflet could cause laceration of the tissue, leading to residual leak. The patch material is usually autologous or bovine pericardium (Figure 5). 


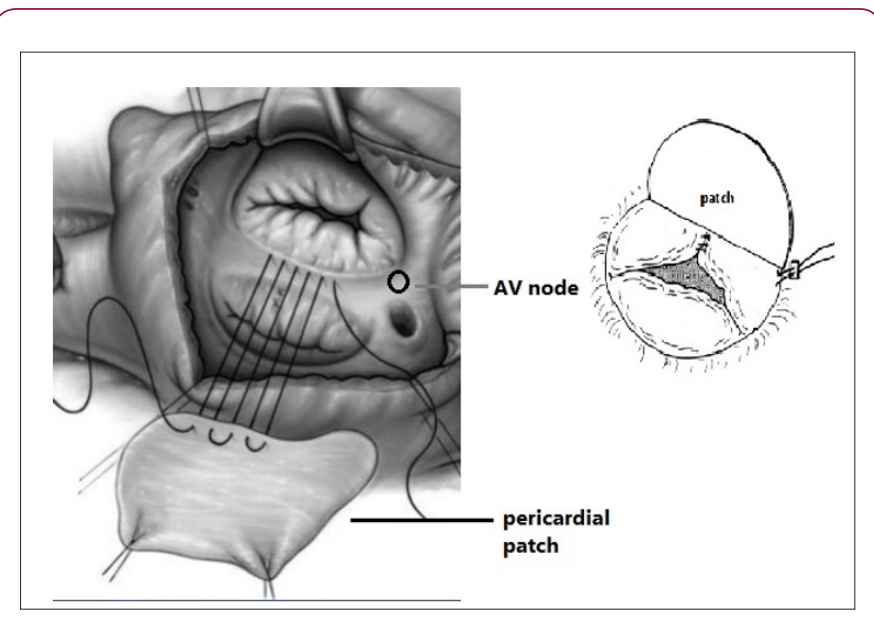

Figure 5: Closure of cleft and repair of partial AV canal defect.

\section{Repair of Complete AV Canal Defects}

Classic Single-Patch: The classic single-patch technique uses a single pericardial patch to achieve this goal. Fresh or glutaraldehydetreated autologous pericardium is the choice of patch material with this repair. One of the most critical point of the procedure is the partition of the common valve (superior and inferior bridging leaflets) into two appropriate halves. The common AV valve is cut, and the patch is inserted in such a fashion that the lower portion of the patch closes the ventricular component of the defect, the AV valves are suspended to the patch, and the upper portion of the patch closes the atrial component (Figure 6).

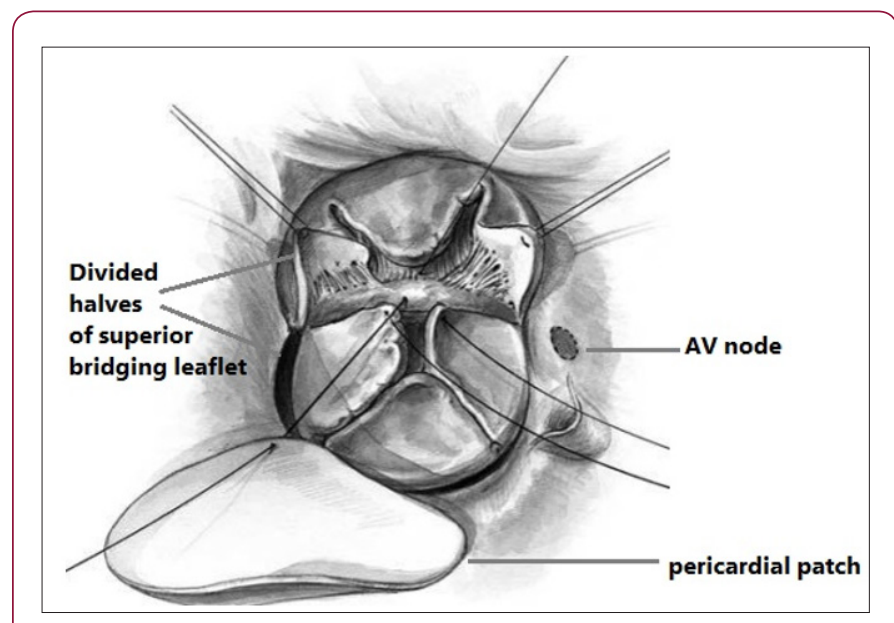

Figure 6: Classic single patch repair.

Modified Single-Patch (Australian) Technique: The main principle of the repair is to sandwitch the superior and inferior bridging leaflets between the scoop out interventricular septum and pericardial patch. Closure of the cleaft and the rest of the defect are the same as in the classic single patch repair (Figure 7).

Double Patch Technique: With this technique, atrial and ventricular components of the defect are closed using separate patches. For ventricular component, Dacron or PTFE material and for atrial defect autologous or bovine pericardium are used. Some authors do not prefer to divide the superior and inferior bridging leaflets during the repair of the ventricular defect. To improve the exposure, some chord attaching to the leaflet tissue away from the free margins needs to be cut. The rest of the repair is completed standardly (Figure 8).

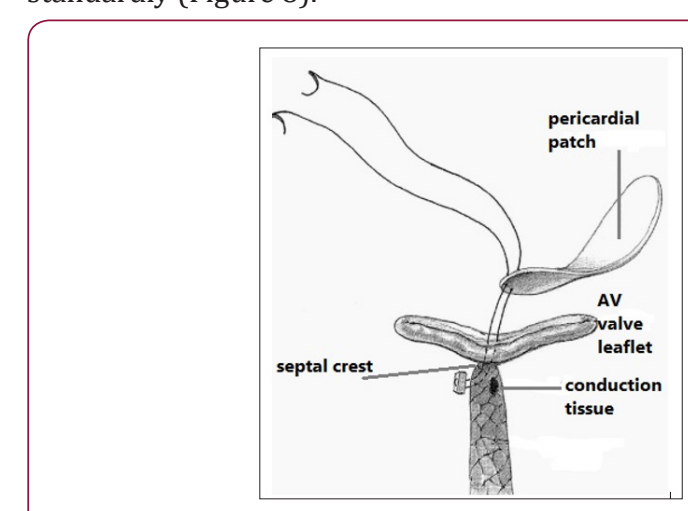

Figure 7: The AV leaflets are sandwitched between setral crest and the patch in modified technique.

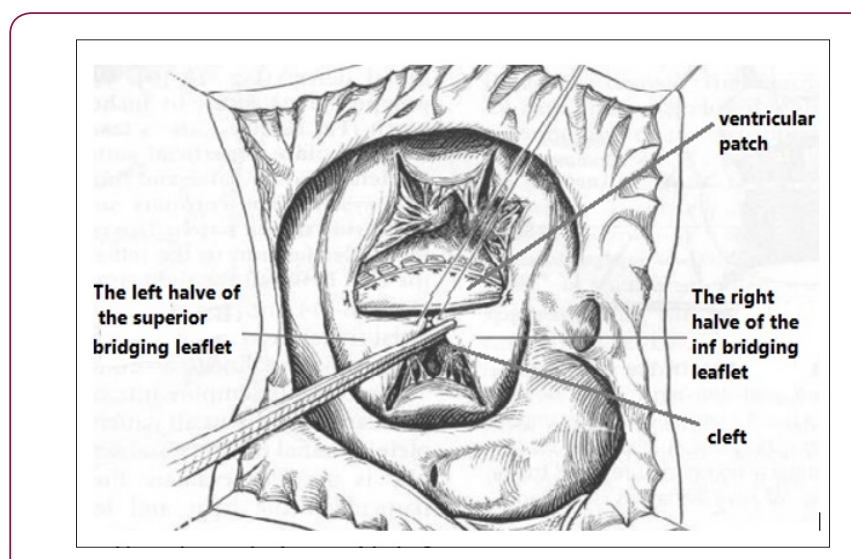

Figure 8: Double patch repair by division of the leaflets.

\section{Conclusion}

Partial AV canal defects represents approximately $25 \%$ of all AV canal defects. Although these defects show very similar physiology with secundum-type ASDs, there are known to be more complex in terms of morphology. Currently, the perioperative mortality and postoperative complete heart block rates have been reported to be minor after repair of partial AV canal defects. On the other hand, the most common indications for reoperation after surgery remain to be left AV valve dysfunction (almost 10\%) and left ventricular outflow tract stenosis (10 to $15 \%$ ) in the long term [3]. After repair, in addition to the fixation of the valve leaflet to the scooped-out septal crest, several inherent morphological features like abnormal cordal and papillary architecture are the main causes of LVOT stenosis. For complete AV canal defects, there are many studies comparing the impact of their above mentioned techniques on operative mortality, late mortality, injury to the conducting system, left AV valve stenosis and insufficiency, residual ventricular level shunting, left ventricular outflow tract obstruction and need for reoperation for left $A V$ valve insufficiency in the literature,. Comparison of the studies of three different repair techniques are given in Table 1. 
Table 1: Comparison of three different surgical techniques in the literature (CSP: classic single patch, MSP: modified single patch, DP: double patch).

\begin{tabular}{|c|c|c|c|c|c|}
\hline & $\begin{array}{c}\text { Total } \\
\text { Number of } \\
\text { Pts (N) }\end{array}$ & $\begin{array}{c}\text { Early } \\
\text { Mortality } \\
(\%)\end{array}$ & $\begin{array}{c}\text { Late } \\
\text { Mortality } \\
\text { (\%) }\end{array}$ & $\begin{array}{c}\mathbf{3}^{\text {rd }} \text { Degree } \\
\text { Block (\%) }\end{array}$ & $\begin{array}{c}\text { Late MV } \\
\text { Reop } \\
\text { (\%) }\end{array}$ \\
\hline CSP & 350 & 4.8 & 4 & 9.7 & 2.3 \\
\hline MSP & 200 & 2 & 0 & 2 & 0.5 \\
\hline DP & 889 & 3.5 & 2.1 & 7.2 & 2 \\
\hline
\end{tabular}

In 2008, Crawford reported the results of 88 complete AV canal defect patients who underwent repair via classic single patch technique. There were no early and late mortality. Complete heart block was reported in 3 patients and 9 of the patients after procedure required mitral valve reoperation [4]. Prifti et al reported their results with classic single patch technique in $190 \mathrm{AV}$ canal patients weighing less than $5 \mathrm{~kg}$. The early and late mortality rate were $8,4 \%$ and $7,4 \%$, respectively. While the rate of complete heart block was subtle (in only 3 patients), 23 patients needed late mitral reoperation during follow up [5]. Similarly, in a report by Reddy et al. [6], 72 patients who underwent surgical repair via classic one patch technique were reported. Only one patient with early and 1 with late mortality were given. Complete heart block was seen in 1 patient and none required late reoperation for mitral valve during a median follow up of 24 months. The outcome of modified singlepatch (Australian) technique in complete AV canal defects was initially described by Dr. Nunn [7] and the 30-day mortality rate was reported as $1.6 \%$.

The percentage of patients who needed reoperation on the mitral valve was reported to be $2.3 \%$ incidence of and none of the patients had left ventricular outflow tract obstruction requiring operation in the follow-up period. Jonas et al. [8] reported very good results with almost zero morbidity and mortality after modified single patch technique. In a report by Backer et al, the authors compared double patch technique with modified single patch technique and stated that modified single patch technique is the best method of repair in complete AV canal defects [9]. Indeed the cross-clamp and CPB times were significantly lower in modified single patch group compared to the double patch group (26 and 29 minutes shorter, respectively). Likewise, Wilcox et al reported the similar finding [10]. Backer et al. [9] insisted on the fact that the major advantage of modified single patch technique is the avoidance of reoperation for mitral regurgitation in follow up and, therefore, they stopped doing double patch technique in 2006 and completely switched to modified single patch technique. On the other hand, it was speculated by some authors that the presence of a large ventricular component of the defect might jeopardize the quality of repair modified single patch technique [10]. However, this finding has net been supported by other authors [9]. Lastly, the major critique of the modified single-patch technique was the higher risk of post repair left ventricular outflow tract obstruction due to the pushing of the superior leaflet down toward the left ventricular outflow. Similarly, this finding was not supported by Jonas and Wilcox' findings $[8,10]$.
In comparison, there have been more reports about the results of double patch repair in $\mathrm{AV}$ canal defects in the literature. In a metaanalysis by Backer et al, a total of 889 patients who underwent AV canal repair using double patch technique was reported. Although the rates of early and late mortality were found to be similar among three techniques, the rate of late mitral valve regurgitation was said to be higher after double patch repair (Table 1) [11]. As is the case for classic single patch technique, one of the main concerns about double patch technique is division of $\mathrm{AV}$ valve leaflets during repair. It has been claimed that dividing the common leaflet and then reattaching inevitably sacrifices valve tissue. This could be more important in infants in whom the scarified area constitutes a greater portion of the valve. In a study by Fortuna et al. [12], it was shown that division of the common valve may lead to distortion of the remaining valve tissue and increased tension on the cleft closure, leading to regurgitation and increased risk of cleft dehiscence. They concluded that division of the bridging leaflets is a risk factor for $\mathrm{AV}$ valve regurgitation (moderate or greater) during the first year after repair. In a report by Backer et al. [13], data related to 173 patients was published. The operative mortality was $6 \%$ and $4 \%$ of the patients had pacemaker implantation for third degree AV block. Moreover, $8 \%$ of the patients had reoperation for left $\mathrm{AV}$ valve in the follow up. Similar results were given by other investigators [14]. In conclusion, nowadays AV canal repair are done with low operative mortality and morbidity in many centers and outcome did not differ by the surgical technique.

\section{References}

1. Jacobs ML, Jacobs JP, Jenkins KJ, Gauvreau K, Clarke DR, et al. (2008) Stratification of complexity: the Risk Adjustment for Congenital Heart Surgery-1 method and the Aristotle Complexity Score--past, present, and future. Cardiol Young 18 Suppl 2: 163-168.

2. Franklin RCG, Béland MJ, Colan SD, Walters HL, Aiello VD, et al. (2017) Nomenclature for congenital and paediatric cardiac disease: the International Paediatric and Congenital Cardiac Code (IPCCC) and the Eleventh Iteration of the International Classification of Diseases (ICD11). Cardiol Young 27(10): 1872-1938.

3. Manning PB (2007) Partial atrioventricular canal: pitfalls in technique. Semin Thorac Cardiovasc Surg Pediatr Card Surg Annu p. 42-46.

4. Crawford FA (2007) Atrioventricular canal: single-patch technique. Semin Thorac Cardiovasc Surg Pediatr Card Surg Annu 10: 11-20.

5. Prifti E, Bonacchi M, Bernabei M, Adrian Crucean, Bruno Murzi, et al. (2004) Repair of complete atrioventricular septal defects in patients weighing less than $5 \mathrm{~kg}$. Ann Thorac Surg 77(5): 1717-1726.

6. Reddy VM, McElhinney DB, Brook MM, Parry AJ, Hanley FL (1998) Atrioventricular valve function after single patch repair of complete atrioventricular septal defect in infancy: how early should repair be attempted? J Thorac Cardiovasc Surg 115(5): 1032-1040.

7. Nunn GR (2007) Atrioventricular canal: modified single patch technique. Semin Thorac Cardiovasc Surg Pediatr Card Surg Annu 10: 28-31.

8. Jonas RA (2004) Complete atrioventricular canal. In RA Jonas, J DiNardo, PC Laussen (Eds.), Comprehensive Surgical Management of Congenital Heart Disease, Arnold Publishers, London, Uk, pp. 397-398.

9. Backer CL, Stewart RD, Bailliard F, Kelle AM, Webb CL, et al. (2007) Complete atrioventricular canal: a comparison of the modified singlepatch technique to the two-patch technique. Ann Thorac Surg 84(6): 2038-2046. 
10. BR Wilcox, DR Jones, EG Frantz, Brink LW, Henry GW, et al. (1997) Anatomically sound, simplified approach to repair of "complete" atrioventricular septal defect. Ann Thorac Surg 64(2): 487-494.

11. Backer CL, Stewart RD, Mavroudis C (2007) What is the best technique for repair of complete atrioventricular canal? Semin Thorac Cardiovasc Surg 19(3): 249-257.

12. Fortuna RS, Ashburn DA, DeOliveira NC, Burkhart HM, Konstantinov IE, et al. (2004) Atrioventricular septal defects: effect of bridging leaflet division on early valve function. Ann Thorac Surg 77(3): 895-902.

ISSN: 2574-1241

DOI: 10.26717/BJSTR.2018.10.001930

Koray Ak. Biomed J Sci \& Tech Res

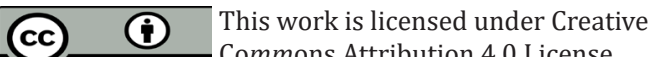

Submission Link: https://biomedres.us/submit-manuscript.php
13. CL Backer, C Mavroudis, ET Alboliras, Zales VR (1995) Repair of complete atrioventricular canal defects: results with the two-patch technique. Ann Thorac Surg 60(3): 530-553.

14. Litwin SB, Tweddell JS, Mitchell ME, Mussatto KA (2007) The double patch repair for complete atrioventricularis communis. Semin Thorac Cardiovasc Surg Ped Card Surg Annu 10: 21-27. 